\title{
Mobile-assisted Language Learning Using WeChat Instant Messaging
}

\author{
https://doi.org/10.3991/ijet.v12i02.6681 \\ Zijuan Shi \\ Shaoyang University, Shaoyang, China \\ zijuanshi@126.com \\ Gaofeng Luo* \\ Shaoyang University, Shaoyang, China \\ gfluo@ 126. com \\ Le He \\ Université du Québec à Trois-Rivières, Trois-Rivières, Canada \\ 5906834 esina.com
}

\begin{abstract}
China has a long-standing problem in second-language education, that is, the lack of communicative learning opportunities. This study attempts to solve the problem by introducing mobile-assisted language learning with WeChat instant messaging. WeChat is one of the most popular instant messaging applications in China. It offers five advantages for education: multifunctionality, individuality, accessibility, interactivity, and affordability. 50 students participated in a one-semester program. They were divided into two groups. One group learned English with the assistance of mobile applications (WeChat Group), and the other learned English without assistance (Control Group). A pre-test and a post-test were given, and the scores were analyzed. The results showed that students in the WeChat group significantly improved in English proficiency. The results suggest that mobile-assisted language learning helps to create language immersion, which effectively motivates the learners further. Therefore, mobile-assisted language learning is promising in English learning for college students.
\end{abstract}

Keywords-English learning, mobile-assisted language learning, WeChat

\section{Introduction}

English learning has always been considered by students a significant challenge in China. Now with the development of wireless network and mobile devices, it is possible to learn English anytime and anyplace. Mobile phones are used as a handy tool for language learning. According to the 38th Statistical Report on Internet Development in China, the number of mobile Internet users as of June 2016 had reached 656 million. Among the total Chinese netizens, the proportion of those using mobile phones to access the Internet was $92.5 \%$ [1]. That is, smartphones have 
become the most important device for Internet access. Mobile Internet applications have penetrated every aspect of users' lives with the improvement of mobile communication networks and the popularization of smartphones. Mobile education, which provides personalized learning scenarios, the experience of touching mobile devices' screens, voice output, and other functional advantages, has become the mainstream of online education. WeChat is a popular instant messaging application, with more than 800 million users worldwide. It has given rise to a new form of social life, and has provided a new way of learning. It is a cross-platform and multifunctional social networking application. The various and powerful functions of WeChat can be applied to language learning. This paper aims to develop a new method of English learning with the assistance of WeChat instant messaging, improving language immersion and enhancing the learners' motivation.

\section{State of art}

Mobile learning (M-learning) is a self-paced learning supported on mobile phones, tablets, or pads. Given the rapid development of network infrastructure and the considerable increase of mobile network speed, the usage rate of the $3 \mathrm{G} / 4 \mathrm{G}$ network has largely increased. Furthermore, Wi-Fi Internet usage has accelerated with the deployment of wireless networks at home, at work, and in public places. M-learning allows learners to learn for as long as a mobile signal is available. Compared with traditional face-to-face education or PC-end education, M-learning provides an individualized learning experience and generates cross-platform interactions through touch screens and voice output to increase the fun of learning.

Laurillard (2007) and Sharples (2007) agreed that mobile devices offer five advantages for education: portability, accessibility, learning opportunities, connection, and personal experience. Therefore, access to education has become simpler with mobile devices, and learning opportunities have become bountiful [2-3]. Peters (2009) argued that mobile devices offer individualized and personal experiences and described mobile devices as "unique scaffolding that can be customized to the individual's path of investigation." He claimed that mobile devices give students "anytime, anywhere learning" [4]. Kukulska-Hulme (2008) and Miangah (2012) noted that mobile-assisted language learning (MALL) provides students with rich, real-time, convenient, social contact, collaborative, and contextual learning [5-6]. Various channels, such as Facebook groups, Twitter, WhatsApp, and WeChat, are available for learners, each with different characteristics [7]. Peslak (2010) used the theory of reasoned action (TRA) to explore the behavior of instant messaging at a small university in the US [8]. DWK Chu (2015) pointed out that students' positive attitudes regarding WeChat/WhatsApp for language learning have strongly influenced their behavioral intentions in their use of WeChat/WhatsApp for Chinese and English reinforcement [9].

WeChat is a popular instant messaging app that provides a great opportunity to achieve ubiquitous learning. It has the following advantages for language learning. 
(1) Multi-functionality. Diversiform messages can be enjoyed and shared by learners, which increases learners' motivation to learn English.

(2) Individuality. Smartphones and wireless networks provide students a chance for "anytime anywhere learning." The learning process is self-paced and individualized.

(3) Accessibility. Approximately $91.7 \%$ of mobile Internet users in China access the Internet via the $3 \mathrm{G} / 4 \mathrm{G}$ network [1]. Wi-Fi networks are readily available at urban public places. Thus, learners can easily access the Internet when they have a smartphone.

(4) Interactivity. Group chat promotes interaction between students and teachers, which expands learning beyond the classroom.

(5) Affordability. WeChat users can send free messages and make free voice and video calls. Messaging is free for a long as users already have an existing Internet data plan.

The remainder of this work is structured as follows. Section 3 discusses the theoretical basis of MALL and establishes a MALL model using WeChat. The experimental results of rigorous analyses are reported in Section 4. Finally, the concluding remarks are provided in Section 5.

\section{$3 \quad$ Methodology}

The main reason for Chinese students' poor performance in English is the limitation of communicative exposure to English at school and in the society. Language immersion is immensely significant for second-language learners. We try to construct a mobile-assisted learning model using WeChat to generate language immersion.

\subsection{Participants}

A total of 50 sophomores from the Department of Foreign Languages of Shaoyang University who participated in the study were divided into two groups. One group learned English with the assistance of mobile devices (WeChat Group), and the other without them (Control Group). Each group had 25 participants. All students who participated in the program had the same curriculum at school. Pre-test results showed no significant difference in the average English proficiency between the two groups.

\subsection{Technical tool}

WeChat is a cross-platform instant messaging app designed for smartphones. WeChat supports five major operating system platforms: Android, iOS, Symbian, Windows Phone, and BlackBerry, which are the top five global smartphone operating systems and account for $99.4 \%$ of the market share. [10] WeChat is one of the largest standalone messaging apps by monthly active users. The number of WeChat users has increased rapidly since its first release in January 2011. The number of active WeChat 
users in the world reached 864 million as of June 2016. The accelerating tendency of WeChat active users is shown in Fig. 1 (including overseas WeChat users).

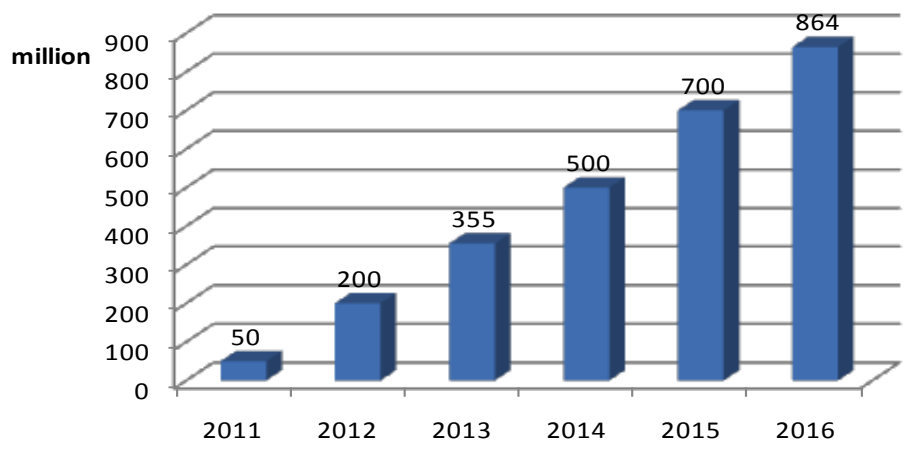

Fig. 1. Number of WeChat active users

According to the data report of WeChat, the number of daily logged-in users had reached 768 million by September 2016, with a 35\% year-over-year growth. Approximately $50 \%$ of users use WeChat for at least 90 minutes a day [11], 20.9\% of WeChat users access WeChat 5-10 times a day, and 16.5\% users access WeChat more than 50 times daily, as shown in Fig. 2 [12].

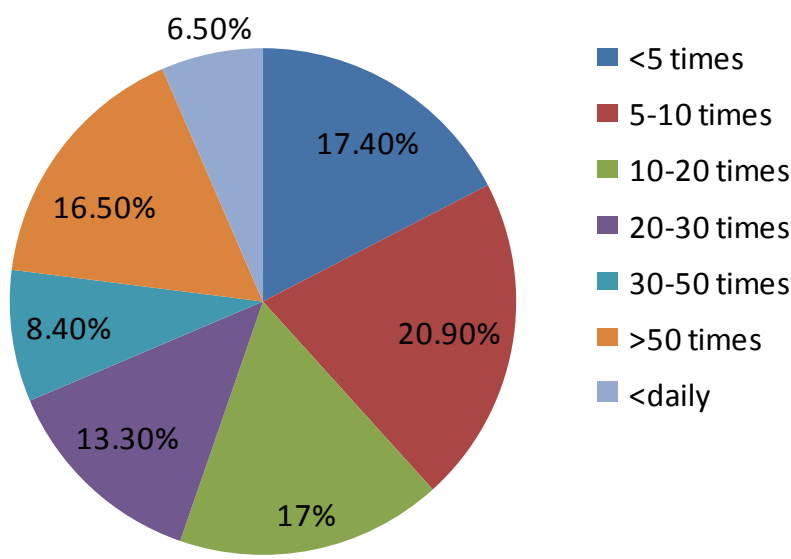

Fig. 2. Frequency of users' daily access to WeChat

These figures illustrate that WeChat has become a part of people's day-to-day activities. Mobile devices are an essential factor of the program. Thus, every participant must have a tool for mobile learning. We conducted a survey on the usage of mobile devices and instant messaging apps before the program. The results of the survey are shown in Table 1. 
All students had a smartphone of their own and that all the smartphones had been installed with WeChat beforehand. The participants had already been using WeChat before they joined in the program. They were thus familiar with the functions of WeChat. Approximately $54 \%$ of the students used WeChat more than 1 hour daily, and $20 \%$ of the students used WeChat for more than two hours every day. The survey illustrates that college students use WeChat often. WeChat was thus a readily available language-learning tool for the participants of the present study.

Table 1. Usage habit of smartphone owners

\begin{tabular}{|l|l|l|l|l|}
\hline \multicolumn{1}{|c|}{ Questions } & \multicolumn{3}{|c|}{ Answers (percentage of the item ) } \\
\hline $\begin{array}{l}\text { 1. How often do you use } \\
\text { WeChat every day? }\end{array}$ & $\begin{array}{l}\text { Very often. } \\
(48 \%)\end{array}$ & Sometimes. (31\%) & Seldom. (21\%) & Never. (0\%) \\
\hline $\begin{array}{l}\text { 2. How often do you use } \\
\text { your smartphone to learn } \\
\text { English? }\end{array}$ & Very often. (12\%) & Sometimes. (35\%) & Seldom. (43\%) & Never. (10\%) \\
\hline $\begin{array}{l}\text { 3. How long do you access } \\
\text { the Internet every day? }\end{array}$ & $\begin{array}{l}\text { More than 3 } \\
\text { hours. (23\%) }\end{array}$ & $\begin{array}{l}\text { More than 2 } \\
\text { hours. (37\%) }\end{array}$ & $\begin{array}{l}\text { More than 1 hour. } \\
(28 \%)\end{array}$ & $\begin{array}{l}\text { Less than 1 hour. } \\
(12 \%)\end{array}$ \\
\hline $\begin{array}{l}\text { 4. How long do you use } \\
\text { WeChat every day? }\end{array}$ & $\begin{array}{l}\text { More than 3 } \\
\text { hours. (8\%) }\end{array}$ & $\begin{array}{l}\text { More than 2 } \\
\text { hours. (20\%) }\end{array}$ & $\begin{array}{l}\text { More than 1 hour. } \\
(54 \%)\end{array}$ & $\begin{array}{l}\text { Less than 1 hour. } \\
(18 \%)\end{array}$ \\
\hline
\end{tabular}

\subsection{MALL model using WeChat}

25 participants were asked to join the WeChat group (Chat Group 1). A foreign teacher, Mike, was invited to the chat group as an online tutor. Mike would provide timely edits or feedback. The teacher chose a topic for the students to discuss on a daily basis. The students could discuss this topic by sending text or voice messages. Five small chat groups were set up: vocabulary, grammar, listening, oral, and writing groups. Each small chat group had a certain focus. For example, in the vocabulary group, participants would chat about memorizing new words, sharing vocabulary with others, or playing several vocabulary games in the group. Participants in the grammar group could discuss grammar rules, correct grammar mistakes made by their peers, or accomplish grammar exercises. All the participants were welcome to join the small chat groups according to their own interests. Each participant could join a maximum of three small chat groups. In the small chat groups, participants focused on one particular theme and aimed to improve one aspect of their English learning. Participants were required to communicate only in English in all the chat groups.

An official account was registered just before the program started. Individuals could register a subscription account through WeChat's self-service platform using a Chinese ID, a Chinese mobile phone number, and a Chinese fixed-line number. All the participants were required to follow the subscription account. Teachers facilitated learning content with participants every day via the subscription account. The content included articles, pictures, and videos. Teachers also released a WeChat micro class on the subscription account once a week. The structure of the WeChat official account is shown in Fig. 3. 


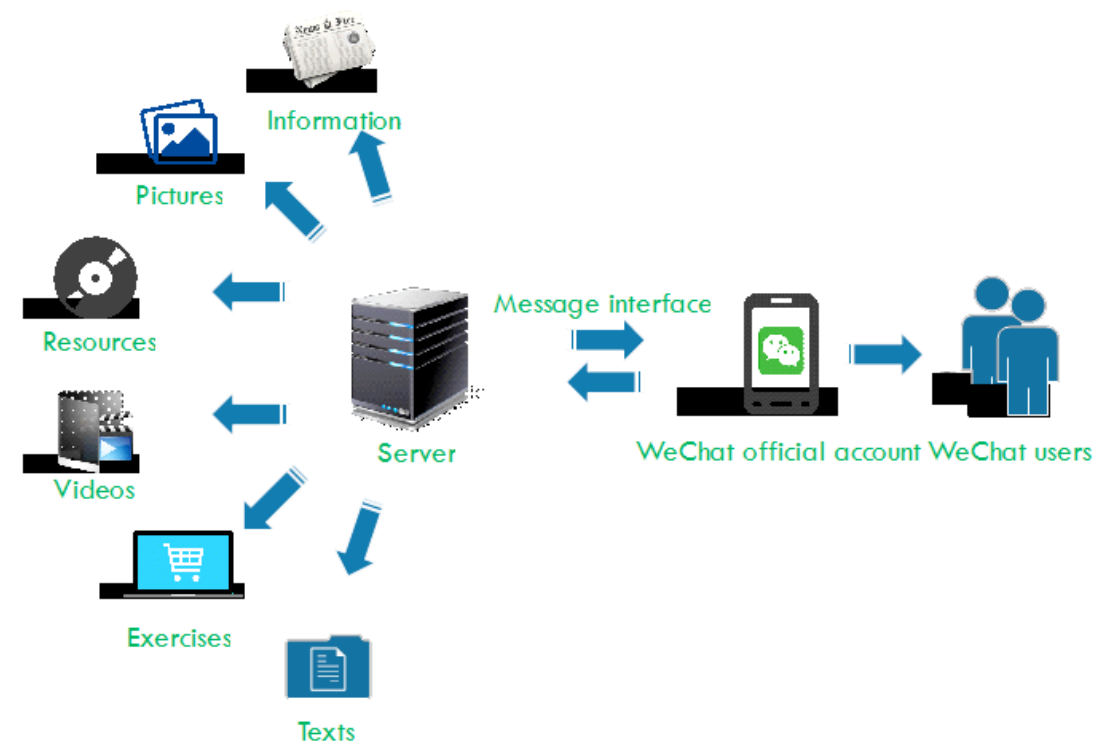

Fig. 3. Structure of WeChat official account

A virtual immersion environment was created with the use of WeChat. Learners were exposed to a virtual English environment by chatting in the groups and learning materials from the official account. The sample data of Chat Group 1 and the micro class are shown in Fig. 4.

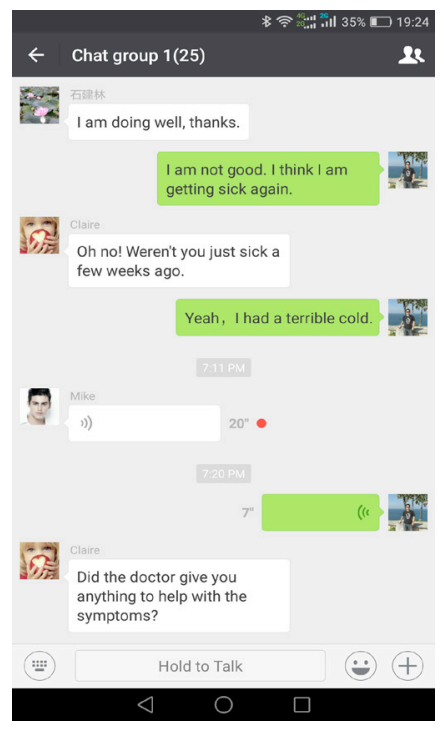

a) Sample data of Chat Group 1

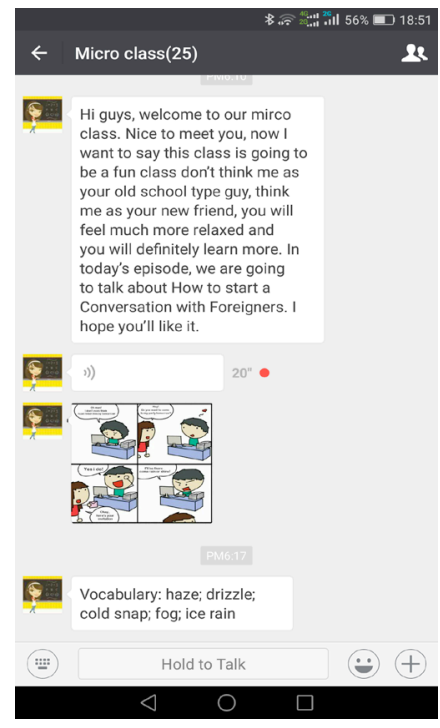

b) Sample data of micro class

Fig. 4. 
Learners were asked to participate in Chat Group 1 from 7 p.m. to 8 p.m. every day. They communicated with peers in English through text or voice messages. The online tutor, Mike, would provide timely revisions if mistakes in grammar, sentence structures, or expressions existed. The presence of an online tutor helped the success of the online interactions. Learners were encouraged to chat in the five small chat groups for at least one hour a day. The chatting hours in small chat groups were flexible. Anyone could suggest a chat topic at any time. The peers in the group could provide responses synchronously or asynchronously. The picture of Fig. 4 a records a small section of the chat history of participants. Several students started a chat and Mike also joined in the conversation. They could chat with text messages or voice messages. The picture of Fig. $4 \mathrm{~b}$ shows that the lecturer delivered a micro class, which was presented by texts, voice messages, and pictures. The micro class made the students feel innovative, and students could interact with lecturer during and after the micro class.

\section{$4 \quad$ Result analysis and discussion}

The pre-test was given to every participant at the beginning of the semester. A post-test was conducted at the end of the semester. The scores of the pre-test and posttest were used as principle measurements to quantify their English learning. Chat histories in every chat group were recorded as transcripts for investigation. Participants in the WeChat Group received questionnaires at the end of the program and were required to answer the questions truthfully. The pre-test and post-test had same kinds of questions and difficulty to ensure the reliability of the test results. The results were analyzed using the statistical software, SPSS, to test whether the MALL model was effective in English learning. The results of the two tests are shown in Table 2 .

Table 2. Results of the two tests in Wechat Group and Control Group

\begin{tabular}{|l|c|c|c|c|c|c|}
\hline \multicolumn{1}{|c|}{ Group } & $\begin{array}{c}\text { Number of } \\
\text { samples }\end{array}$ & $\begin{array}{c}\text { Average pre-test } \\
\text { score }\end{array}$ & $\begin{array}{c}\text { Average post-test } \\
\text { score }\end{array}$ & Gain & t & P \\
\hline WeChat Group & 25 & 73.16 & 84.35 & +11.19 & 2.8 & 0.001 \\
\hline Control Group & 25 & 73.45 & 76.68 & +3.23 & -0.2 & 0.000 \\
\hline
\end{tabular}

Table 2 shows that the average pre-test scores in WeChat Group and Control Group are similar. The results indicate no significant differences in the language proficiencies of the students from both groups. The average pre-test score of the WeChat Group is slightly lower than that of the Control Group, but an independent sample t-test showed no evident difference between the two groups' average pre-test scores $(\mathrm{t}=-0.01, \mathrm{P}=0.78>0.05)$. The data show that the WeChat Group and Control Group had made progress by the end of the semester. Notably, the average post-test score of the WeChat Group is comparatively higher than that of the Control Group. After a semester-long experiment with mobile immersion learning, the average posttest score of the WeChat Group was 84.35, which is higher than its average pre-test 
score by 11.19 points. The average post-test score of the Control Group was higher than the average pre-test score by 3.23 points. The independent sample t-test shows a significant difference in the post-test results $(\mathrm{t}=3.23, \mathrm{P}=0.041<0.05)$. The post-test scores of the WeChat Group were higher than that of the Control Group. Moreover, the paired sample t-test showed significant differences in test scores in the WeChat Group before and after a semester of experimental teaching $(\mathrm{t}=2.8, \mathrm{P}=0.001<0.05)$. The students' average scores significantly increased. Thus, the mobile-assisted learning model is more effective in promoting the students' English proficiency than the model without mobile-assisted learning.

A questionnaire on learners' attitudes toward the mobile-assisted language learning was given to the WeChat Group participants at the end of the semester-long program. The questionnaire had four structural items and an open question. A total of 25 questionnaires were distributed to the participants in the WeChat group. 25 questionnaires were returned, but only 24 of the questionnaires were valid. The questionnaire is shown in Table 3. The results are shown in Fig. 5.

Table 3. Questionnaire on learners' attitudes toward mobile-assisted learning

\begin{tabular}{|l|l|l|l|l|}
\hline \multicolumn{2}{|c|}{ Questions } & \multicolumn{3}{c|}{ Choices } \\
\hline $\begin{array}{l}\text { Do you think that learning English with } \\
\text { WeChat is convenient? }\end{array}$ & $\begin{array}{l}\text { A. Very } \\
\text { convenient }\end{array}$ & $\begin{array}{l}\text { B. } \\
\text { Convenient }\end{array}$ & $\begin{array}{l}\text { C. Not } \\
\text { convenient }\end{array}$ & $\begin{array}{l}\text { D. Do not } \\
\text { know }\end{array}$ \\
\hline $\begin{array}{l}\text { Do you think mobile-assisted learning is } \\
\text { beneficial for college students? }\end{array}$ & $\begin{array}{l}\text { A. Very } \\
\text { beneficial }\end{array}$ & B. Beneficial & C. Vain & $\begin{array}{l}\text { D. Do not } \\
\text { know }\end{array}$ \\
\hline Do students actively interact in chat groups? & A. Very active & B. Active & C. Inactive & $\begin{array}{l}\text { D. Do not } \\
\text { know }\end{array}$ \\
\hline $\begin{array}{l}\text { Is the official account useful for language } \\
\text { learning? }\end{array}$ & A. Very useful & B. Useful & C. Not useful & $\begin{array}{l}\text { D. Do not } \\
\text { know }\end{array}$ \\
\hline $\begin{array}{l}\text { What is your evaluation and suggestion of } \\
\text { mobile-assisted learning? }\end{array}$ & & & \\
\hline
\end{tabular}

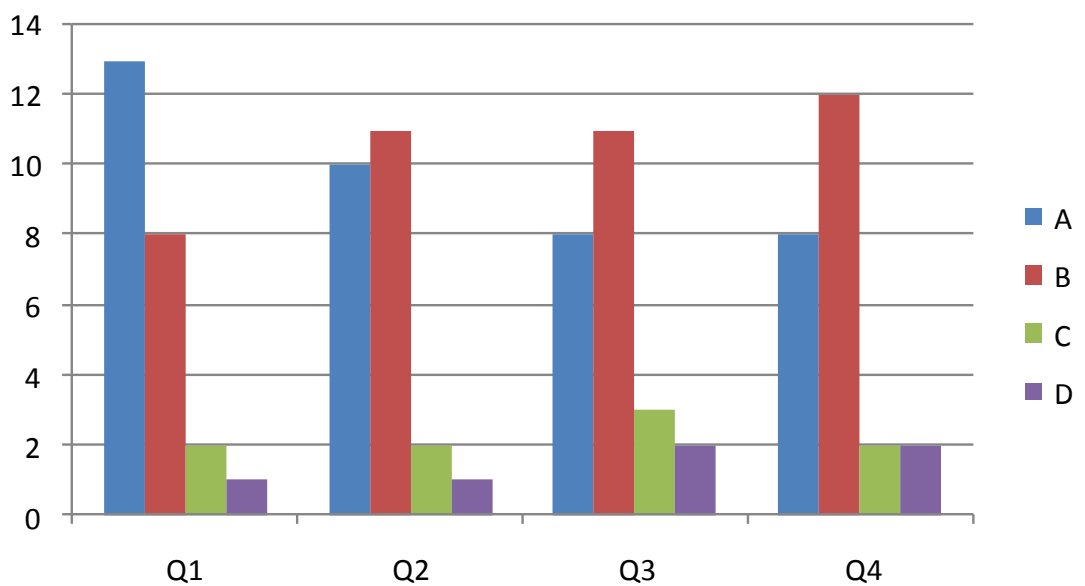

Fig. 5. Results of the questionnaire on learners' attitudes 
When asked about the convenience of using WeChat in English learning, 54\% of the students responded that WeChat is very convenient for its multi-functionality, accessibility, and interactivity. Approximately $34 \%$ of the students responded that it is convenient. Only two students thought that it was inconvenient, and one student did not know whether WeChat was convenient.

With regard to the question, "Do you think the mobile-assisted learning is beneficial for college students?", $41 \%$ of the students believed that the mobileassisted learning is very beneficial, $46 \%$ considered it as beneficial, $8 \%$ thought that mobile-assisted learning was useless, and $4 \%$ were undecided.

Regarding how actively the students interacted in the chat groups with WeChat, $33 \%$ of the students confirmed that they were very active in the chat groups, $46 \%$ stated that they were active, $13 \%$ admitted that they were inactive in the chat groups, and $8 \%$ answered that they did not know. Most students actively performed in chat groups. Several students sent more than 200 messages a day when chatting with their teammates. They were willing to chat with teammates in English. A few students performed negatively in the chat groups because they were afraid of making mistakes and felt uncomfortable chatting in English.

When asked about the usefulness of the official account, $33 \%$ of the students confirmed that the official account was very useful, $50 \%$ thought it was useful, $8 \%$ of the students denied its usefulness, and $8 \%$ students answered that they did not know how useful the account was for them. Most students believed that the official account was useful for obtaining learning materials and that the micro class was an effective method to learn English.

The last item in the questionnaire was an open question. The students were asked to evaluate and suggest improvements for mobile-assisted learning. A number of the answers are listed as follows:

- It makes me more motivated to learn English.

- I feel comfortable chatting with others in English now.

- I have learned a lot in the semester-long program.

- Content pushed by official account is useful and interesting.

- Sometimes smartphones are distracting and would interfere with my other activities.

- I wish more foreigners are invited to the chat groups.

- I wish teachers provide more micro class.

- I want to continue using WeChat to practice English.

Language immersion was achieved to a certain degree using the MALL model in the program. Participants generally regarded this learning model in a positive manner. Most of them were very interested in the mobile-assisted learning model and provided good responses in English vocabulary, sentence making, speaking, and writing. Most students considered WeChat as an effective tool that motivates them to learn English. 


\section{Conclusions}

This study sought to improve students' English proficiency by using WeChat instant messaging. The features and advantages of WeChat were discussed, and a MALL model using WeChat was designed. An empirical study was conducted to show that MALL model is beneficial for English learning. The data analysis and questionnaire results revealed the following.

(1) A virtual language immersion was created using WeChat instant messaging. Learners were exposed to a virtual English environment where they were encouraged to communicate in English as thoroughly as possible. This kind of immersion helped students to practice English and gradually improved their English proficiency.

(2) Students were very interested in mobile-assisted English learning. Most of the students in the WeChat Group performed actively in the new learning model. They effectively interacted with peers and tutors using text and voice messages. Official accounts also provided a new way of learning for students.

(3) With enhanced learning efficiency, learners were nurtured with a strong sense of confidence. Their confidence in writing and speaking English improved.

The mobile-assisted language learning model was proven to effectively enhance learners' interest and improve their English proficiency. However, this study also has a number of limitations. For example, several students who lacked learning autonomy had difficulty continuing over time, and students are at risk for mobile phone addiction. Therefore, further research should identify such existing problems. Further experiments should be conducted to deepen the study of mobile-assisted language learning.

\section{Acknowledgment}

This work was supported in part by the Educational Science Planning Group of Hunan Province (XJK16BYY03) and the Research Foundation of the Education Bureau of Hunan Province (12B115, 12C0863).

\section{$7 \quad$ References}

[1] CNNIC, Statistical Report on Internet Development in China (July 2016), retrieved from http://cnnic.com.cn/IDR/ReportDownloads/201611/P020161114573409551742.pdf.

[2] Laurillard, D. Pedagogical forms for mobile learning, In N. Pachler (Ed.), Mobile learning: Towards a research agenda. London, U.K.: WLE Centre, Institute of Education, 2007.

[3] Sharples, M. Big issues in mobile learning: Report of a workshop by the Kaleidoscope Network of Excellence in Mobile Learning Initiative. Nottingham, U.K.: University of Nottingham, 2007.

[4] Peters, K. M-learning: Positioning educators for a mobile, connected future, In M. Ally (Ed.), Mobile learning: Transforming the delivery of education and training. Vancouver: Marquis Book Printing, 2009. 
Paper- Mobile-assisted Language Learning Using WeChat Instant Messaging

[5] Kukulska-Hulme, A., \& Shield, L. An overview of mobile assisted language learning: From content delivery to supported collaboration and interaction, ReCALL, 2008, vol. 20(3), pp. 271-289. https://doi.org/10.1017/S0958344008000335

[6] Miangah, T., \& Nezarat, A. Mobile-Assisted Language learning, International Journal of Distrusted and Parallel Systems (IJDPS), 2012, vol. 3(1), pp. 309-319. https://doi.org/10.5121/ijdps.2012.3126

[7] E. Bones, P. Hasvold, E. Henriksen, and T. Strandenaes. Risk analysis of information security in a mobile instant messaging and presence system for HealthCare, Int. J. Med. Eng. Informat., 2006, vol. 76(9), pp. 677- 87. https://doi.org/10.1016/j.ijmedinf. 2006.06.002

[8] A. Peslak, W. Ceccucci, and P. Sendall, An empirical study of instant messaging behaviour using Theory of Reasoned Action, J. Behav. Appl. Manag., 2010, vol. 11(3), pp. 263-278.

[9] DWK Chu, KK Ng, IKW Lai and PWM Lam. Analysis of student behaviors in using WeChat/ WhatsApp for language learning at diploma level in Hong Kong, International Symposium on Educational Technology. 2015, pp. 104-108. https://doi.org/10.1109/ iset.2015.29

[10] TM Miangah and A Nezarat, Mobile-Assisted Language Learning, International Journal of Distributed and Parallel Systems, 2012, Vol. 3(1), pp. 309-319. https://doi.org/10.5121/ ijdps.2012.3126

[11] Chatterbox, The 2016 WeChat Data Report, Retrieved from http://blog.wechat.com/2016/ 12/29/the-2016-wechat-data-report/ - more-4961.

[12] TMTPOST, WeChat User Globe Report 2015, Retrieved from http://www.tmtpost. com/1021929.html.

\section{Authors}

Zijuan Shi is a lecturer in the Department of Foreign Languages, Shaoyang University, Shaoyang 422000, China (zijuanshi@126.com).

Gaofeng Luo (corresponding author) is an associate professor in Information Engineering Department, Shaoyang University, Shaoyang 422000, China. He also works at the Key Laboratory of Information Service in Rural Southwestern Hunan, Shaoyang. He is a member of China Computer Federation (CCF) (gfluo@126.com).

Le $\mathrm{He}$ is a postgraduate in the Department of Leisure, Cultural and Tourism Studies, Université du Québec à Trois-Rivières, Trois-Rivières QC G9A 5H7, Canada (5906834@sina.com).

Article submitted 20 January 017. Published as resubmitted by the authors 21 February 2017. 